\title{
RESEARCH
}

\section{Development of A Situational Judgment Test to Assess ACPE Standards 3 And 4}

\author{
Teresa DeLellis, PharmD, ${ }^{\mathrm{a}}$ Marwa Noureldin, PharmD, MS, PhD, ${ }^{\mathrm{a}}$ Sharon K. Park, PharmD, MEd, ${ }^{\mathrm{b}}$ Kelly M \\ Shields, PharmD, ${ }^{\mathrm{c}}$ Alicia Bryant, PharmD, MS, ${ }^{\mathrm{d}}$ Aleda M. H. Chen, PharmD, PhD ${ }^{\mathrm{e}}$ \\ ${ }^{a}$ Manchester University, College of Pharmacy, Fort Wayne, Indiana \\ ${ }^{\mathrm{b}}$ Notre Dame of Maryland University, School of Pharmacy, Baltimore, Maryland \\ ${ }^{c}$ Ohio Northern University Raabe, College of Pharmacy, Ada, Ohio \\ ${ }^{\mathrm{d}}$ University of the Incarnate Word, Feik School of Pharmacy, San Antonio, Texas \\ ${ }^{\mathrm{e}}$ Cedarville University, School of Pharmacy, Cedarville, Ohio
}

Corresponding Author: Teresa DeLellis, Manchester University, College of Pharmacy, 10627 Diebold Rd, Fort Wayne, IN 46845. Tel: 260-470-4053. Email: TMDeLellis@ manchester.edu

Submitted December 10, 2020; accepted June 16, 2021; ePublished July 2021

\begin{abstract}
Objective. To successfully meet competencies related to ACPE Standards 3 and 4, it is essential for pharmacy programs to assess student progression in the affective domain. The purpose of this study was to develop and assess evidence of validity for a situational judgment test (SJT) that encompasses Standards 3 and 4.

Methods. A multi-institutional faculty team developed an 18-item SJT (scenarios asking the respondent to rank the effectiveness of four approaches) mapped to Standards 3 and 4. The group systematically reviewed the literature, , created items, and iterated until consensus was achieved. Subject matter experts (SME) reviewed and provided feedback on the instrument. Students from two institutions were recruited for cognitive interviewing on the finalized instrument. Cognitive interview data were analyzed for themes.

Results. After edits to the instrument based on SME feedback, students $(n=18)$ in the cognitive interviews. identified item length as a concern and commented on item/response clarity and comprehensiveness . Data from the cognitive interviews were used to modify the SJT to reduce length and clarify items. The result was two shorter versions of the instrument both with similar mapping to all elements in Standards 3 and 4.

Conclusion. Early steps of validating an SJT suggest the instrument may be a promising tool to assess student progression in the affective domain. The SJT instrument is intended to provide evidence of the development that occurs in didactic, experiential, and co-curricular education as part of a comprehensive assessment plan. Further validation is in progress to establish this instrument.
\end{abstract}

Keywords: co-curriculum, situational judgment test, validity evidence, ACPE standards, affective domain, cognitive interviewing

\section{INTRODUCTION}

The goal of pharmacy education is to produce well-rounded, competent pharmacists ready to face the challenges of an ever-evolving health care field and to demonstrate practice and team-readiness. Standards 2016 by the Accreditation Council for Pharmacy Education (ACPE) include an intentional focus on the curriculum, co-curriculum, and experiential curriculum working in harmony to develop team-ready, practice-ready pharmacists. Compared to past standards, Standards 2016 specifies the provision and the assessment of co-curricular activities as a necessary component in pharmacy programs, in addition to demonstration of students' clinical and practice knowledge. ${ }^{1}$ Standards 3 and 4 focus on affective domain skills and are adopted from American Association of Colleges of Pharmacy (AACP)'s Center for the Advancement of Pharmacy Education (CAPE) Educational Outcomes 2013. ${ }^{2}$ Standard 3 focuses on skills necessary for pharmacy practice and patient care, including problem solving, education, patient advocacy, interprofessional collaboration, cultural sensitivity, and communication. Standard 4 focuses on essential components of personal and professional development, including self-awareness, leadership, innovation and entrepreneurship, and professionalism. ${ }^{1}$ Together, Standards 3 and 4 are typically reinforced within the co-curriculum of pharmacy programs, and Appendix 3 notes using co-curricular experiences as part of the required documentation, along with curricular components, to develop competence in the affective domain. ${ }^{1}$

Since the adoption of the Standards, pharmacy programs have developed a variety of ways to provide, track, and assess elements of their co-curriculum. A national survey of pharmacy programs indicated that the most common method for documenting completion of co-curricular requirements was student reflections. ${ }^{3}$ While this assessment method is valuable, allowing students to practice self-awareness and critically self-assess their performance, there are challenges 
with quantifying and evaluating data from these assignments. There is also often added workload for pharmacy programs to evaluate these reflections in a systematic and timely manner. For many of the outcomes identified in Standards 3 and 4 , there are no readily available comprehensive assessment instruments. This makes it challenging to determine whether or not graduates are adequately equipped with those affective-domain related competencies. In the absence of an assessment with evidence of validity, it is not only difficult to assess key elements of Standards 3 and 4, but also to track students' growth and advancement in these areas throughout their time in a pharmacy program. Thus, there is a need to create comprehensive instruments with validity evidence that can supplement self-assessment measures.

One potentially valuable approach to measure affective skills is with situational judgement tests (SJT). ${ }^{4,5}$ SJTs are low fidelity simulations designed to assess judgement in situations that emphasize non-academic skills. Scenarios are constructed to reflect a situation likely to be encountered in practice and individuals are asked to respond to this hypothetical scenario. With SJTs, there are often no "correct" responses. ${ }^{5,6}$ Instead, for each scenario, participants are provided a list of possible responses and asked to identify the best course of action. Each response can be individually rated for appropriateness or the responses can be ranked in relation to one another for appropriateness. ${ }^{4-6}$ Responses of individuals are compared with those provided by content experts, which are provided a priori. SJTs are based on the expectation that past behavior or knowledge is a good predictor of future behavior. ${ }^{4-6}$ SJTs have a history of use in a variety of professional disciplines as part of the hiring process to identify the most qualified applicants. ${ }^{5}$ More recently, their use has been seen in admissions screening for medicine, where they have demonstrated predictive validity superior to knowledge- and cognitive ability-based tests. ${ }^{7}$ In these approaches, SJTs are more commonly utilized to identify student understanding of what they should do in a scenario. Less has been published on the use of SJTs in pharmacy programs. ${ }^{5,9}$ SJTs also tend to perform well across demographic groups. ${ }^{8,10}$ The few SJTs that have been developed and evaluated have covered a few domains, such as empathy and professionalism; these SJTs have demonstrated evidence of validity and potential value as measurable standardized assessments or for formative assessments. ${ }^{5,11,12}$

Demonstrating evidence of validity for any instrument is an important component of the instrument development and refinement process. ${ }^{13}$ The cognitive interview (CI) method has increasingly been employed during the survey development process to ensure the overall quality of an instrument and to identify factors that attribute to response errors. In addition, it is one method for providing evidence of content validity and is used to determine what and how survey items should be revised. ${ }^{14}$ The main purpose of $\mathrm{CI}$ is to determine whether or not study participants interpret the survey items in the way intended by the researcher, ${ }^{15}$ and misalignments between the researcher and the respondent can be elucidated. ${ }^{14}$ Thus, the focus of this interview method is not on the person providing a response to the question, but on the survey question. ${ }^{14,16} \mathrm{CI}$ has been successfully used in other pharmacy education studies. ${ }^{17}$

Given the lack of readily available standardized assessments and the potential utility of SJTs, the purpose of this study was to develop and demonstrate initial validity evidence for a SJT instrument designed to assess competence relating to key elements in ACPE Standards 3 and 4. Such an instrument can be used to measure student pharmacists' growth in competencies over time (ie, student progression and competency level) with reduced impact on program resources.

\section{METHODS}

A three-phase process was utilized to develop and demonstrate face and content validity evidence of a SJT instrument assessing the ten key elements (hereafter referred to as domains) of Standards 3 and 4. These elements include problem solving, education, patient advocacy, interprofessional collaboration, cultural sensitivity, communication, selfawareness, leadership, innovation and entrepreneurship, and professionalism. For an overview of the methodology, please see Figure 1. More details on each of these phases follow.

Prior to Phase One, a group of 20 faculty who were members of the AACP Assessment Special Interest Group conducted a comprehensive literature review to identify any previously developed instruments for each domain in ACPE Standards 3 and 4. The individuals had expertise in assessment, along with additional expertise in social and administrative sciences, drug information, and clinical sciences. Some of the members had experience in instrument development. The instruments found were student self-assessment scales and surveys; however, a comprehensive assessment tool encompassing all of the Standard 3 and 4 domains was lacking. It was determined that a SJT was the best approach for assessing the affective domains based on prior studies. ${ }^{5,11}$ Thus, the faculty workgroup initiated the threephase process to develop such an instrument, with guidance from scales found in the literature review as background for item development.

In Phase One, the research team divided up into 10 small working groups to create SJT items for each domain of Standards 3 and 4. The goal was to construct two or three scenarios per domain that would contain four response options and be ranked. While each scenario was designed to primarily address one domain, due to the nature of the scenarios, they often addressed multiple domains. When dealing with patient or professional interactions, several domains will often 
overlap due to the nature of these interactions and required skillsets. For example, many items mapped to communication in addition to a primary domain, such as professionalism.

Four responses to each SJT scenario item were devised to illustrate different actions that could be taken, displaying skills in the corresponding domain. The instruments identified during the literature review, as mentioned earlier, were utilized as a guide during the idea generation phase of the responses to provide ideas for the research subgroup. The subgroup members created a set of responses that could be represented clearly in a written SJT format. The appropriateness of each response was determined via a modified Delphi method that consisted of a consensus-building, iterative discussion process among the research team. The responses were subsequently rank ordered to determine the extent to which each response met the domain outcome, with the more appropriate response having the higher score. Currently, with SJTs, there is no one scoring approach that is considered better than others. ${ }^{6}$ The scoring algorithm was as follows: four points if all options were ranked correctly, three points if three options were ranked correctly, two points if two options were ranked correctly, one point if one option was ranked correctly, zero points if zero options were ranked correctly. The team then verified the mapping of each SJT item to Standards 3 and 4, with the option to map scenarios that functionally assessed more than one domain to multiple domains, working until consensus was met. Initial item generation resulted in the development of 22 items. Items that could not achieve $100 \%$ consensus were eliminated $(n=4)$, resulting in 18 items. For these four items, consensus could not be achieved on stem and option clarity or ideal ordering of answer choices. The entire working group reviewed the scenarios and finalized the SJT (Appendix 1).

In Phase Two, eight additional experts in both assessment and affective domain subject matter from outside the working group reviewed and provided feedback on the instrument. The subject matter experts (SMEs) were selected based on either formal training in or significant scholarly contributions to their respective fields. SMEs were asked to suggest improvements, verify mapping, examine the rank-order of responses, and provide any areas that needed clarification. Three assessed the entire instrument (SJT and affective domain assessment SMEs), and five assessed the scenarios designed to address affective domains within their realm of expertise (education, interprofessional education, leadership, and professionalism). SMEs were sought for these four domains specifically based on recommendations of the working groups that created questions to assess those domains. After each SME provided comments, members of the research team met to discuss feedback and implement changes before disseminating to the next SME. The SJT was considered appropriately vetted after two consecutive SMEs returned the instrument without change suggestions. Wording changes made from these reviews resulted in the version used for the CI phase of pilot testing. No items were removed as a result of Phase Two processes.

In Phase Three, CI was conducted with current student pharmacists in four-year PharmD programs to elicit student understanding of each item for clarity, consistency in interpretation, and appropriateness of items. Students were recruited from two programs, Cedarville University and Manchester University, via emails sent out to all students in these professional programs, with a goal of obtaining up to 10 interviews per institution. These institutions were chosen due to their extensive involvement in the project and having researchers with experience in cognitive interviewing. Fifteen students (eight from Cedarville University and seven from Manchester University) volunteered and were interviewed, representing all four years in the PharmD program from each institution. The CI method can be divided into two techniques: think-aloud and verbal probing. ${ }^{14}$ The method of verbal probing can be concurrent or retrospective. This study used concurrent verbal probing which requires asking additional specific questions intended to elicit more information after the study participant answered a question. The goal of this method is to learn more about a cognitive process followed in answering a question. ${ }^{17}$

With each student who agreed to participate, one-hour sessions were scheduled to complete the CI. At each interview, students were briefly provided the purpose of the study, informed that the session would be audio-recorded for data analysis purposes, and asked to provide verbal consent to participate. All students provided consent to participate as designated in the study IRB approval. Since the full SJT instrument was long, each student was assigned a random list of questions from the full instrument to answer. Each student was asked to read a SJT item and answer the question. Students were encouraged to read and think out loud as long as it did not interfere with their understanding. After providing their ranked responses, a research team member asked additional probing questions to gain additional insight into how students interpreted the question, their judgment related to the items and responses, what issues they faced when determining their rankings, and address any clarity or inconsistency with the item or the responses. Last, students were asked what skills each SJT item addressed as an open-ended question. While this was not a primary goal of the development of the SJT and was minimally discussed during the cognitive interviews, the goal of asking this question was to determine if students understood the underpinning concepts in the questions related to affective domain skills. The interviewers took detailed notes of each session. The interviews also were audio-recorded and transcribed verbatim by a trained research assistant. Students completed questions until the one-hour time slot had passed, they had finished all of the questions, or decided to stop answering questions. 
Based on transcribed interviews and notes taken, three researchers (AC, MN, RB) met to discuss common themes with regards to item clarity and length as well as instrument length and any other issues that arose during the sessions. Preliminary themes were disseminated to the full research group, and they iteratively revised the SJT until consensus was achieved. Two researchers (AB, TD) then reviewed the interview transcriptions to confirm themes and that all necessary changes had been discussed.

\section{RESULTS}

Upon development of an 18-item SJT instrument, for Phase Two, the SJT was sent to a total of eight SMEs for review. Comments returned primarily consisted of suggestions for shortening the content in each scenario or the assessment overall. SMEs also suggested changes to some answer choices within their expert domains to more clearly delineate a difference in competency among answer choices and more closely align with real-life practice situations. A summary of changes by SME domain is provided in Table 1.

For Phase Three, a total of 15 students were recruited and participated in cognitive interviewing (Cedarville University = eight students, Manchester University = seven students). At least three students from each year in the professional program (P1-P4) participated (Table 2). Students identified scenario and response length as a concern. Large themes that emerged were: (1) length of the scenarios and response options, (2) clarity of the scenarios and responses, and (3) suggestions of more suitable responses than presented to the students. Most students could not complete more than four-eight scenarios in a 45-60 minute cognitive interview session. For example, one student stated, "I think that if a little more information was in the prompt and not in the answer choice it could maybe cut down on the wording because all the answers were very long." Another student reported, "Some of the questions are just kind of wordy which is kind of required to get a good understanding of some of the questions but just like this one in particular was just like extremely long."

Students also felt some scenarios were clear, but some questions could be rephrased to be more concise and straight-forward. For example, one student found a scenario very clear, "I liked the question; it was well worded. The answers were easy enough to understand and it does show an issue that is had in the workplace." Another student found a different scenario more challenging, "I wasn't sure like what B was implying... . So that was a little unclear. Yeah and because I didn't know exactly I assumed that that meant... so I picked that as one. But I might have picked A as my first choice if I knew that he was doing that in English."

In some scenarios, students proposed alternative responses that may be optimal in place of the options listed. For example, one student noted on a scenario that they would have wanted "to ask to speak to the physician directly and just have a chat." They did not want to go through another individual to resolve a patient problem. Another student wanted to expand the approach to include an "evidence-based solution of trends by other pharmacists in the department, so it's not just you recognizing the errors because it may not be an error on other people's ends." When presented with a listing of the elements from ACPE Standards 3 and 4, students appropriately identified many of the domains to the scenarios as originally mapped by the research team or similar skills, even if they did not know which answer was best in the scenario. For example, students often indicated that the scenarios were addressing "interprofessional communication," "problemsolving," "communication," or "making good judgments."

The cognitive interview process identified that students had to really think through several of the answers, weighing which ones were optimal. For example, one student noted, "It was hard to choose the answers in some sort of order just because there were so many competing good ideas." Another noted, "I definitely think I have a response that's the most effective, but I'm not sure if I can decide between a couple of the others." That student then discussed their thought process regarding how they ranked further questions.

Data from the CIs were used to modify the SJT in the following ways. First, items were modified to enhance clarity according to student feedback on the responses and reduce both item and response length. Second, it was determined that the 18-item instrument needed to be reduced in size to ease the cognitive burden on students who will be administered the instrument for assessment purposes. As such, two versions were created, nine items each, that were comparable in terms of domains assessed. (Table 3) Institutions could use either version in assessing students and potentially rotate versions to decrease test-retest limitations. In the original instrument, nine of the 10 domains had two questions written for each, with communication integrated in multiple items. After dividing the SJT into two versions based on primary domain assessed, item mapping across all 10 domains remained substantially similar across both versions. Thus, the split between the two versions was performed to ensure at least one question per primary domain was included in each version. (Table 3)

\section{DISCUSSION}


The SJT was developed in a similar approach as others who have created SJTs for use in pharmacy education.,11 Patterson and colleagues developed a SJT to assess integrity, empathy, team involvement, and critical thinking/problemsolving, while Smith and colleagues developed a SJT to assess professionalism. ${ }^{5,11}$ In both studies, investigators developed scenarios and utilized SMEs to refine their instrument through several rounds before moving to psychometric evaluation. ${ }^{5,11}$ In the present study, we also utilized two approaches to establish content validity. First, subject matter experts (SMEs) were approached for a multiple iterative process until consensus was reached. Second, cognitive interviewing was performed with a group of student pharmacists which enabled further refinement of the scenarios and responses. Based on CI, the SJT was split into two parallel versions that addresses all domains while reducing cognitive burden on students taking the assessment. Additional psychometric testing is currently underway to further refine the SJT.

As mentioned, CI was used as a method of instrument refinement and to provide further evidence of content validity prior to psychometric testing. CIs provide an opportunity to determine if study participants interpreted the survey items in the way authors intended ${ }^{15}$ and could address any differences in interpretation. ${ }^{14}$ Students did highlight several aspects that were not interpreted as intended in addition to determining that the SJT was too long. Thus, the information from the CI resulted in more clear and concise scenario and response items as well as two shortened versions of the SJT instrument. Reducing the length also allows the instrument to be completed in a shorter time, while still mapping to all 10 elements of Standards 3 and 4. Increased length of scenarios in SJTs can increase the cognitive load of the instrument. ${ }^{18}$

While further validity evidence of this instrument is needed and is currently being conducted, a SJT designed to assess ACPE Standards 3 and 4 could be useful for institutions as part of the broader assessment of the affective domain components. ${ }^{1}$ Because, by nature, the written SJT can only be designed to assess certain skills within each affective domain, it should be used as part of a comprehensive assessment plan in concert with other assessment techniques, including direct observation, self-assessment reflections, and other assignments utilizing standardized rubrics. ${ }^{19}$ The SJT could be used to benchmark student progress throughout the curriculum and provide additional data within the assessment plan regarding student competency attainment.

Several limitations should be noted, including conducting the CI at only two institutions both of which are private institutions and located in the Midwest, which may impact generalizability. Future iterations will assess additional student pharmacist populations (ex: institution types, geographic regions, racial/ethnic groups) to increase generalizability. In addition, the rankings of the response items may be subjective and can vary between practicing pharmacists. The multiple iterative process with several SMEs helps ensure that the scenarios, items, and response options have been peer-reviewed and examined for intended outcomes. Other limitations include potential variations in the delivery of CI and data collection among research team members, even though the researchers met beforehand to ensure consistency. Despite the limitations, this is the first study to address all of the domains within ACPE Standards 3 and 4, utilizing a single instrument, a SJT. Second, the use of cognitive interviewing among students as an approach of providing further evidence of content validity allowed for refinement of the instrument and ensured that feedback was received from the intended audience for the SJT.

Additional demonstration of validity is in progress including piloting the two versions at multiple institutions, administering to preceptors to identify benchmarks for minimum competency, and conducting psychometric testing. The final instrument would provide a more objective, less faculty time-intensive assessment approach that could be included as part of a larger holistic assessment of ACPE Standards 3 and 4.

\section{CONCLUSION}

This study describes the development and initial testing of an SJT instrument aimed at addressing the affective domains associated with ACPE Standards 3 and 4. Results provide early evidence of content validity of the instrument as demonstrated by subject matter expert consensus and cognitive interviewing with student pharmacists. Such instruments may be a promising tool to assess student competency and progression in the affective domain during their education and identify any gaps in competency attainment. This can provide pharmacy programs valuable information to aid in modification of curricular and/or co-curricular activities. Psychometric analysis and further refinement and testing of the SJT instrument is currently in progress.

\section{ACKNOWLEDGEMENTS}

The authors would like to thank subject matter experts Sarah Gordon, Melissa Rasmussen, Kathryn Smith, Michelle Farland, Kristin Janke, Heather Petrelli, Katie Axford, and Russell Attridge for contributing to creation and revision of the SJT instrument, and Robert D. Beckett for assisting with cognitive interviewing.

\section{REFERENCES}


1. Accreditation Council for Pharmacy Education. Accreditation standards and key elements for the professional program in pharmacy leading to the Doctor of Pharmacy degree: "Standards 2016". Accessed November 17, 2020, https://www.acpe-accredit.org/pdf/Standards2016FINAL.pdf

2. Medina MS, Plaza CM, Stowe CD, et al. Center for the Advancement of Pharmacy Education 2013 educational outcomes. Am J Pharm Educ. 2013;77(8):162. doi: 10.5688/ajpe778162.

3. Maerten-Rivera JL, Chen AMH, Augustine J, et al. Co-curriculum implementation and assessment in accredited Doctor of Pharmacy programs. Am J Pharm Educ. 2020;84(3):7569. doi:10.5688/ajpe7569

4. Patterson F, Zibarras L, Ashworth V. Situational judgement tests in medical education and training: Research, theory and practice: AMEE Guide No. 100. Medical Teacher. 2016/01/02 2016;38(1):3-17. doi:10.3109/0142159X.2015.1072619

5. Smith KJ, Flaxman C, Farland MZ et al. Development and validation of a situational judgement test to assess professionalism. Am J PharmEduc. 2020;84(7):7771. DOI: https://doi.org/10.5688/ajpe7771

6. Whetzel DL and McDaniel MA. Situational judgment tests: an overview of current research. Human Resource Management Review. 2009;19:188-202. doi:10.1016/j.hrmr.2009.03.007

7. Webster ES, Paton LW, Crampton PES, Tiffin PA. Situational judgement test validity for selection: A systematic review and meta-analysis. Medical Education. 2020;54(10):888-902. doi:10.1111/medu.14201

8. Patterson F, Ashworth V, Zibarras L, Coan P, Kerrin M, O'Neill P. Evaluations of situational judgement tests to assess non-academic attributes in selection. Medical Education. 2012;46(9):850-868. doi:10.1111/j.13652923.2012.04336.x

9. Wolcott MD, Lobczowski NG, Zeeman JM, McLaughlin JE. Exploring the role of knowledge and experience in situational judgment test responses using mixed methods. Am J Pharm Educ. 2020:ajpe8194. doi:10.5688/ajpe8194

10. Schmitt N, Keeney J, Oswald FL, et al. Prediction of 4-year college student performance using cognitive and noncognitive predictors and the impact on demographic status of admitted students. J Appl Psychol. Nov 2009;94(6):1479-97. doi:10.1037/a0016810

11. Patterson F, Galbraith K, Flaxman C, Kirkpatrick CMJ. Evaluation of a situational judgement test to develop non-academic skills in pharmacy students. Am J Pharm Educ. 2019;83(10):7074. doi:10.5688/ajpe7074

12. Wolcott MD, Lupton-Smith C, Cox WC, McLaughlin JE. A five-minute situational judgment test to assess empathy in first-year student pharmacists. Am J Pharm Educ. 2019;83(6):6960. doi:10.5688/ajpe6960

13. Peeters MJ, Harpe SE. Updating conceptions of validity and reliability. Res Social Adm Pharm. Aug 2020;16(8):1127-1130. doi:10.1016/j.sapharm.2019.11.017

14. Peterson CH, Peterson NA, Powell KG. Cognitive interviewing for item development: Validity evidence based on content and response processes. Measurement and Evaluation in Counseling and Development. 2017/10/02 2017;50(4):217-223. doi:10.1080/07481756.2017.1339564

15. Collins D. Pretesting survey instruments: An overview of cognitive methods. Quality of Life Research. 2003/05/01 2003;12(3):229-238. doi:10.1023/A:1023254226592

16. Ryan K, Gannon-Slater N, Culbertson MJ. Improving survey methods with cognitive interviews in small- and medium-scale evaluations. American Journal of Evaluation. 2012;33(3):414-430. doi:10.1177/1098214012441499

17. Karpen SC, Hagemeier NE. Assessing faculty and student interpretations of AACP survey items with cognitive interviewing. Am J Pharm Educ. 2017;81(5):88-88. doi:10.5688/ajpe81588

18. Cabrera MAM, Nguyen NT. Situational judgment tests: A review of practice and constructs assessed. International Journal of Selection and Assessment. 2001;9(1- 2):103-113. doi:10.1111/1468-2389.00167

19. Fulford MJ, Souza JM, Alston GL, et al. Are You CAPE-A.B.L.E.? Center for the Advancement of Pharmacy Education: An Assessment Blueprint for Learning Experiences. Accessed November 6, 2020, https://www.aacp.org/sites/default/files/2017-10/Assessment\%20CAPE\%20Paper-\%20Final\%2011.pdf 
Table 1. Changes Made To Situational Judgment Test Based On The Subject Matter Expert Suggestions

\begin{tabular}{|c|c|c|}
\hline Subject matter expert domain & Feedback received & Changes implemented \\
\hline Education & $\begin{array}{l}\text { Cross mapping needed for each item } \\
\text { (education sub-component of many) }\end{array}$ & $\begin{array}{l}\text { Cross mapping completed for each } \\
\text { item and vetted through each SME }\end{array}$ \\
\hline Interprofessional Education & $\begin{array}{l}\text { Must involve educating other } \\
\text { professions, not merely collaborating }\end{array}$ & $\begin{array}{l}\text { Chose draft scenarios with } \\
\text { educational component }\end{array}$ \\
\hline Leadership & $\begin{array}{l}\text { Must be general enough to apply to } \\
\text { any style of leadership }\end{array}$ & $\begin{array}{l}\text { Adjusted answer choices to reflect } \\
\text { leadership domain general } \\
\text { principles }\end{array}$ \\
\hline Situational Judgement Tests & $\begin{array}{l}\text { Maximum questions for SJT should } \\
\text { be } 25\end{array}$ & $\begin{array}{l}\text { Reduced questions per domain from } \\
3-4 \text { to } 2\end{array}$ \\
\hline Professionalism & No changes necessary & No changes made \\
\hline Affective domain assessment & No changes necessary & No changes med \\
\hline
\end{tabular}

Table 2. Number of students for cognitive interviews by institution and professional program year

\begin{tabular}{llccc}
\hline & $\begin{array}{l}\text { PharmD } \\
\text { Year 1 }\end{array}$ & $\begin{array}{l}\text { PharmD } \\
\text { Year 2 }\end{array}$ & $\begin{array}{l}\text { PharmD } \\
\text { Year 3 }\end{array}$ & $\begin{array}{l}\text { PharmD } \\
\text { Year 4 }\end{array}$ \\
\hline $\begin{array}{l}\text { Cedarville } \\
\text { University } \\
\text { Manchester }\end{array}$ & 1 & 1 & 3 & 1 \\
University & & 2 & 2 & 2 \\
\hline
\end{tabular}

Table 3. Mapping Situational Judgment Test Items To ACPE Standards 3 And 4 Domain

\begin{tabular}{|c|c|c|c|c|c|c|c|c|c|c|}
\hline & $\begin{array}{l}3.1 \\
\text { Probl } \\
\text { em- } \\
\text { Solvin } \\
\text { g }\end{array}$ & $\begin{array}{l}3.2 \\
\text { Educa } \\
\text { tion }\end{array}$ & $\begin{array}{l}3.3 \\
\text { Patien } \\
\text { t } \\
\text { Advoc } \\
\text { acy }\end{array}$ & $\begin{array}{l}3.4 \\
\text { Inter- } \\
\text { professio } \\
\text { nal } \\
\text { Collabor } \\
\text { ation } \\
\end{array}$ & $\begin{array}{l}3.5 \\
\text { Cultur } \\
\text { al } \\
\text { Sensiti } \\
\text { vity }\end{array}$ & $\begin{array}{l}3.6 \\
\text { Communi } \\
\text { cation }\end{array}$ & $\begin{array}{l}4.1 \\
\text { Self- } \\
\text { Aware } \\
\text { ness }\end{array}$ & $\begin{array}{l}4.2 \\
\text { Leader } \\
\text { ship }\end{array}$ & $\begin{array}{l}4.3 \\
\text { Innovation } \\
\& \\
\text { Entreprene } \\
\text { urship }\end{array}$ & $\begin{array}{l}4.4 \\
\text { Profession } \\
\text { alism }\end{array}$ \\
\hline $\begin{array}{l}\text { Vers } \\
\text { ion } \\
\text { A. }\end{array}$ & $\begin{array}{l}1,2 \\
3,4, \\
5,6 \\
7,8,9\end{array}$ & $1,4,5$ & 2 & 3 & 4 & $\begin{array}{l}1,3,4,5 \\
6,7,8,9\end{array}$ & 6,9 & 7 & 7,8 & 4,9 \\
\hline $\begin{array}{l}\text { Vers } \\
\text { ion } \\
\text { B. }\end{array}$ & $\begin{array}{l}1,2 \\
3,4 \\
5,6 \\
7,8,9\end{array}$ & $1,7,9$ & 2,4 & 1,3 & 4 & $\begin{array}{l}1,3,4,5 \\
6,7\end{array}$ & 5,6 & 8 & 2,8 & $5,6,9$ \\
\hline
\end{tabular}


Figure 1. Overview of Study Methodology

Phase I: AACP

Assessment SIG

members create SJT

scenarios

Iteration and

refinement until

consensus

Phase II: Review by

experts (subject matter

experts, assessment

specialists)

Iteration and

refinement until

consensus

Phase III: Student pharmacist cognitive interviews
Iteration and refinement until consensus 
Appendix.

Are you Affective? Situational Judgment Test - Student Version_A

1. A pharmacist (PZ) rounding with an internal medicine team in a hospital has a patient being taken off of aspirin because of a stomach bleed. The patient also has diabetes, increasing the risk of heart attack or stroke, which aspirin can prevent. The team asks PZ to provide discharge education to this patient. Please rank the following statements in order of effectiveness (most to least effective).

\section{Place an " $\mathrm{X}$ " in the box regarding your ranking.}

a. You should stop taking your aspirin because this medication most likely caused your stomach to bleed. I've prepared a handout for you about symptoms to watch for after you go home that you can read and follow

b. Aspirin is what caused your GI bleeding, so you should stop taking this medication. Stopping aspirin could increase your risk of heart attack or stroke, so make sure you monitor closely for angina, aphasia, and other stroke symptoms.

c. Aspirin is what caused your GI bleeding, so you should stop taking this medication. Here is a handout on signs and symptoms you should monitor at home.

d. You should stop taking your aspirin because this medication most likely caused your stomach to bleed. Watch carefully for symptoms like chest pain, difficulty speaking, and other stroke symptoms listed in this handout.

2. A pharmacist $(\mathrm{AH})$ is trying to determine the best new healthcare service to offer in her community pharmacy. AH observes that many patients seem to be on diabetes medications, so AH believes a diabetes management service would be most appropriate for the community. AH needs to decide on the next step for the pharmacy. Please rank the following strategies in order of effectiveness (most to least effective):
Place an " $\mathrm{X}$ " in the box regarding your ranking.
Most
2
Effective
$3 \quad$ Least
Effective

a. Start building the business plan for a diabetes management service

b. Ask patients whether they would be interested in a diabetes management service

c. Perform a patient and provider needs assessment to determine the best service to offer

d. Start adding diabetes education handouts to dispensing materials with each prescription for diabetes

3. A community pharmacist (KD) answers a phone call from a nurse calling in a prescription for a shared patient for Eliquis $5 \mathrm{mg} 1$ tablet twice daily. The nurse asks you to tell the patient to cut the tablets in half and take the halftablet twice daily, but not to include those instructions on the prescription. The patient is having financial difficulties and this will allow it to last two months. However, this would be considered insurance fraud. Please rank the following pharmacist responses in order of effectiveness (most to least effective):
Place an " $\mathrm{X}$ " in the box regarding your ranking.

a. "I can fill it that way this once, but just so you are aware, that is considered insurance fraud. Before this first fill runs out, we should look into some patient assistance programs available from the manufacturer that will be a better option for this patient. A social worker would probably be the best person to help her with that."

b. "It is very considerate of you and the physician to try to help this patient afford her medications. However, doing it in this way may not be the best option for legal reasons. I know there are some patient assistance programs available through the 
manufacturer that would be a better option for this patient. A social worker could probably help us get that started in the most time-effective manner."

c. "I cannot fill a prescription that way as it is considered insurance fraud and will endanger all of our licenses. You should be careful recommending such practices, since I could technically report you myself. We should look into some patient assistance programs available from the manufacturer instead. A social worker would probably be the best person to help her with that."

d. Thank the nurse for the prescription and dispense it as $5 \mathbf{~ m g} 1$ tablet twice daily since it is in the best interest of the patient. It isn't enough money to hurt an insurance company, and since the change was only ordered verbally, there is no record that the pharmacist had anything to do with the fraud. If only more health care professionals cared enough about their patients to take this risk.

4. The population within the neighborhood of a community pharmacy includes a high density of Spanish-speaking immigrants. A woman carrying a bottle of infant Tylenol approaches the pharmacist at the counter with a question. She is holding a 4-month-old girl, and her clothes and hair are disheveled. She introduces herself as Maria Garcia and points to her daughter and asks: "for her, how to take?" Please rank the following pharmacist responses in order of effectiveness (most to least):
Place an " $\mathrm{X}$ " in the box regarding your ranking.

\section{Most}
Effective
2
3

a. Provide MG with a handout in her native language about free medical clinics in the area. Show her where to find the less expensive generic bottle of Tylenol, and recommend she ask a physician about proper infant dosing and side effects.

b. Retrieve the Spanish language Tylenol dosing guide. Walk MG through the information in the guide and ask how much the girl weighs. Based on the weight, show MG the correct dose and frequency. Show her how to draw up the dose and have MG demonstrate it back.

c. Take the bottle, turn it around, and point to the sections about dosing, and indicate to her the ones that would apply to her daughter.

d. Speak slowly while looking at MG. Ask MG how much the girl weighs. Based on the weight, say the following: "Give your daughter one dose every 4 to 6 hours."

5. The pharmacist (JC) approaches a patient waiting at the far side of the pharmacy counter and asks how she can be helped. The patient says "I've been feeling weird lately ever since...(lowering eyes and whispering) 'the change', and my physician told me to put on a patch every three days". The patient proceeds to lift up her shirt exposing her belly where there are at least 15 patches attached to her stomach. Please rank the following responses in order of effectiveness (most to least):

\section{Place an " $\mathrm{X}$ " in the box regarding your ranking.}

\section{Most} Effective

a. JC asks the patient if she would be more comfortable in a patient consultation room. Once there, JC introduces himself and asks her what her physician told her about hormone replacement therapy. While listening, JC says "uh, huh; uh huh" while looking at the patient profile on his clipboard. He tells her all of the information she needs to know. Then, JC asks, "just so I know that I've explained everything correctly, 
can you tell me how you will be using the patches?". The

patient proceeds to explain and when finished, JC says, "it

seems you understand it better now, have a great day" and

extends his hand saying goodbye.

b. JC asks the patient if she would be more comfortable in a patient consultation room. In the consultation room, JC gathers information on what the patient knows, actively engages with her, and explains how to appropriately use patches. JC asks, "just so I know that I've explained everything correctly, can you tell me how you will be using the patches?". The patient proceeds to explain, and JC smiles and says, "I bet you will be feeling much better now, would you please stop back in next week and let me know how you're doing?" He then shakes the patient's hand and says goodbye.

c. Looking back over his shoulder, JC looks at the clock and in a regular speaking voice tells the patient briskly, "The problem is that you are supposed to remove the patch before you put on a new one. Do you have any other questions"?

d. JC notices a long line and asks the patient to go to the patient consultation room to wait for him. Once there, JC quickly explains everything the patient needs to know to use the patches correctly. JC then asks what questions the patient has for him, and the patient says she was confused about the side effects and when she could expect them to go away. JC looks at the long line again and says the side effects will subside once she finally figures out how to use them properly. JC then stands up and walks back to the pharmacy counter.

6. DK's semester is almost half over and becoming harder to manage. DK currently has 5 classes and is overwhelmed with the thought of projects due and upcoming midterms. In addition, DK's roommate continues to leave dishes in the sink and has friends over until after midnight most days of the week. Please rank the following actions in order of most to least effective:
Place an " $\mathrm{X}$ " in the box regarding your ranking.
Most
2
$3 \quad$ Least
Effective
Effective

a. DK contacts her faculty mentor and asks for help devising a calendar ensuring each item is achieved based on the deadline. DK talks with her roommate and lets her know the mess and frequent visitors make it hard for her to study at the apartment, therefore affecting her grades this semester.

b. DK contacts her faculty mentor and asks for help devising a calendar ensuring each item is achieved based on the deadline. After reflecting on how she best studies, DK talks with the roommate to better understand her perspective while sharing her own challenges with studying in the apartment.

c. DK contacts her faculty mentor and asks for help devising a calendar ensuring each item is achieved based on the deadline. After reflecting on how she best studies, DK decides to try to study elsewhere for the rest of the semester.

d. After reflecting on how she best studies, DK texts her roommate and reminds her that "dirty dishes make it hard to study". DK starts studying for tomorrow's test and decides to worry about the rest later.

7. LS recently became a manager at a chain community pharmacy. At the manager meeting, staff shortage is discussed as several pharmacists $(\sim 15 \%)$ left the company to work for competitors. LS has heard that there might 
be some personality conflicts among different managers. LS looks around and everyone is looking down or at their phones. Nobody is taking the lead to get the discussion started. Please rank the following actions in order of effectiveness (most to least):

\section{Place an "X" in the box regarding your ranking.}

\section{Most} Effective

a. LS lets everyone know that she recognizes that they have had their conflicts in the past. However, this staffing shortage affects every store, so they should just put their differences aside and participate in the conversation.

b. There is no reason to dig up past grievances. It's time to start fresh. LS just ignores the awkward silence and starts suggesting solutions. The others will eventually come around and start pitching in.

c. LS is new here and doesn't want to cause any problems. She decides to let the upper management handle the staffing shortage. It is, after all, the company's problem.

d. LS starts by introducing herself and asks each manager to share their perspective, concerns, or reservations, how the staffing shortage has affected them, and a possible solution. LS then compiles solutions and takes a vote on each.

8. IW is a clinical pharmacist practicing in an ambulatory clinic setting. IW is new to the clinic and learns that patient satisfaction scores are chronically low. The clinic director approaches IW and asks him to lead an initiative to address this issue. Please rank the following actions in order of effectiveness (most to least):

$$
\text { Place an " } \mathrm{X} \text { " in the box regarding your ranking. }
$$

a. IW researches the issue and finds a few programs requiring financial investment, but have achieved incredible success at clinics similar to his. He designs a similar but smaller-scale clinic workload adjustment that will likely produce moderate results without cost and minimum inconvenience to office staff and presents this to the clinic director.

b. IW researches the issue and finds a few programs requiring financial investment, but have achieved incredible success in increasing scores at similar clinics. He combines ideas from several of these programs, with modifications to best fit his clinic, and creates a business plan outlining cost and expected return on investment to present to the clinic director.

c. IW researches the issue and comes to the conclusion that staff attitudes are poor and the providers have terrible bedside manner. You recommend the clinic director place special emphasis on this during annual evaluations, helping to change behaviors of those willing to change and eliminating positions of those who will not.

d. IW researches the issue and discovers poor communication amongst clinic providers and staff is a frequent theme at the root of the problem. He designs a short training in appropriate inter-office communication for providers and staff and asks the clinic director to purchase lunch for the clinic to incentivize attendance.

9. DH, an ambulatory care clinical pharmacist, sees on the news that his geographical area has one of the highest HIV rates in the state. When completing his required continuing education credits for license renewal, he identifies an organization offering additional certificates in HIV medication therapy for $\$ 1500$. DH is already worried about his workload and being able to properly care for his current patient load while maintaining a 
healthy relationship with his fiancé, and money is tight while saving for his upcoming wedding. Please rank the following actions in order of effectiveness (most to least):

\section{Place an " $\mathrm{X}$ " in the box regarding your ranking.}

$\begin{array}{cccc}\begin{array}{c}\text { Most } \\ \text { Effective }\end{array} & \mathbf{2} & \mathbf{3} & \begin{array}{c}\text { Least } \\ \text { Effective }\end{array} \\ \end{array}$

a. DH tells his employer he'd like to obtain this certificate to help serve the community. If his employer can adjust his workload to allow time at work to complete the course, DH commits to paying the course fee and explains the benefits of the investment.

b. DH tells his employer he'd like to obtain this certificate to help serve the community. If his employer can fund it for him, DH commits to finding his own time outside of work to complete the course. He provides a breakdown of costs and benefits.

c. DH tells his employer he is interested in this training and asks if they can help with either workload or funding. DH plans to do it either way, even if he has to pay for it himself and take time at home to complete the course.

d. DH tells his employer he'd like to obtain this certificate to help serve the community. However, it will require funding assistance and an adjustment of workload to allow for time to complete the course. He provides a breakdown of costs and benefits.

\section{Are you Affective? Situational Judgment Test - Student Version_Version B}

1. A community pharmacist (VL) is judiciously filling and verifying prescriptions and notices a pattern in which she has to repeatedly call the same physician for mistakes every time he prescribes a particular class of medications. Please rank the following strategies in order of effectiveness (most to least effective):
Place an " $\mathrm{X}$ " in the box regarding your ranking.
Most
2
$3 \quad$ Least
Effective

e. Continue the current course of action, calling about every incorrect prescription. Eventually, the physician will notice the pattern and will change her prescribing habits.

f. Arrange a time to offer an educational session in the physician's office about that class of medications. Create a survey to give out after the meeting to assess how to properly prescribe these medications.

g. Send a fax to the physician's office with a quick educational note about how to properly prescribe this class of medications. Leave contact information at the bottom of the note and ask that the physician calls if he has any questions about the information.

h. The next time VL has to call about this issue, she should educate the phone nurse about how these medications should be prescribed, and ask them to repeat back the information shared.

2. A patient comes to a community pharmacist (KW) asking for a refill of his cholesterol medication and complains that the medication is too expensive and not covered by his insurance. The patient tells KW the physician doesn't listen when he shares concerns related to medication costs. Please rank the following strategies in order of effectiveness (most to least effective):

\section{Place an " $\mathrm{X}$ " in the box regarding your ranking.}

e. Give the patient the name of some medications that would be less expensive and likely covered by insurance 
f. Call the physician's office and strongly convey the cost issues and state that they need to alter the medication

g. Work with the patient to identify covered medications and call the physician's office to make an evidence-based recommendation

h. Recommend the patient takes a half tablet daily to still get some benefit but only get a refill every other month to save money

3. An ambulatory care pharmacist works with a physician, Dr. Thomas, who has referred a patient (SM) with a new diagnosis of Type 2 DM. The pharmacist collects information on SM's lifestyle - diet, exercise, medication beliefs, etc. and learns SM eats free food at his work (McDonald's) due to his financial difficulty. The pharmacist informs Dr. Thomas of this new information. Dr. Thomas responds, "SM just needs to take his medications and his A1c will improve." Please rank the following responses in order of effectiveness (most to least effective):
Place an " $\mathrm{X}$ " in the box regarding your ranking.
Most
2
3
Least
Effective
Effective

e. "You are right, I will try some things to help him adhere to his medications. That will ultimately improve his A1c."

f. "You're wrong. We need to consult social work first. He won't be able to take his medications if we don't address resources."

g. "I agree it is important that he takes his medications in order to improve his A1c. What are your thoughts about also recommending a social work consultation to address the resource issues?"

h. "You're his doctor, It's your call. Just don't be surprised if the patient doesn't meet his A1c goals."

4. An ambulatory care pharmacist (MS) working with a physician group and is referred a 52-year-old male patient with a 10 -year history of type $2 \mathrm{DM}$. During the appointment, the patient indicates he hasn't been taking all his diabetic medications "because there's too many of them." He also mentions his wife lost her job a few months ago and he's a seasonal worker, without much business lately. Please rank the following approaches in order of effectiveness (most to least):
Place an " $\mathrm{X}$ " in the box regarding your ranking.
Most
2
3
Least
Effective
Effective

e. Inquire about why the patient thinks he's on too many medications and if cost is an issue. Indicate the importance of adhering to diabetic medications to avoid major complications in the future, that can be even more costly.

f. Counsel the patient on his medications and inquire about his situation, and if he is feeling sad and unmotivated due to his social situation. Recommend to the physician the patient should be screened for depression and prescribed an antidepressant.

g. Discuss with the patient reasons why he is not taking his medications and if cost is an issue. Go through and modify the medication list so he is on an appropriate and cost-effective regimen.

h. Counsel the patient on his medications and indicate the purpose of each one. Provide the patient with a pill box that would allow him to better keep track of the medications.

5. A pharmacist (SP) has worked for a chain pharmacy for several years and recently became a store manager. At the regional store manager meeting, SP's group is charged with finding solutions to the staffing shortage. Several pharmacists $(\sim 15 \%)$ left the company to work for competitors. One of the other managers, Dave, looks at SP and laughs while saying to the group "she must have just been promoted to cover the shortage" then says, "Why don't 
we promote all the pharmacists so they won't leave, then we can just hire all the recent grads clambering for jobs - problem solved, can we go home now"? Please rank the following responses in order of effectiveness (most to least effective):

\begin{tabular}{|l|l|l|}
\hline \multicolumn{1}{|c|}{ Place an "X" in the box regarding your ranking. } & \multicolumn{1}{|c|}{$\begin{array}{c}\text { Most } \\
\text { Effective }\end{array}$} & \begin{tabular}{|} 
Least \\
Effective
\end{tabular} \\
\hline e. & $\begin{array}{l}\text { SP flushes red on her neck, looks towards the corner of the } \\
\text { room, taps her pen on the table and laughs along with the } \\
\text { group. }\end{array}$ & \\
\hline f. & $\begin{array}{l}\text { SP smiles widely at everyone and says, "Hello, that's a great } \\
\text { segue for me to introduce myself! I'm SP. I know that I'm } \\
\text { newly promoted, but I believe I'm ready to work with you all } \\
\text { as colleagues and look forward to identifying effective } \\
\text { solutions to the current staffing shortage." }\end{array}$ & \\
\hline g. & $\begin{array}{l}\text { SP looks around the room at each of her new colleagues } \\
\text { smiling, stopping at Dave and says "Yes, um, I'm SP. My store }\end{array}$ & \\
was really successful. So, um, I don't think I was promoted \\
because of the shortage. But I understand the concerns."
\end{tabular}

6. Yesterday afternoon, DA, a student pharmacist, completed a topic discussion presentation in class. Based on the rubric from the professor, DA received a 70\% (unnecessarily low in the DA's opinion). There were several comments from the professor on how to improve presentation skills and content. DA must determine how to respond. Please rank the following student responses in order of effectiveness (most to least effective):
Place an " $X$ " in the box regarding your ranking.
Most
2
3
Least
Effective
Effective

e. DA prints out a copy of the comments from the grading rubric. Later in the evening, DA rereads the comments from the professor. DA sends an email to her requesting a meeting to better understand the feedback and improve performance.

f. DA approaches the professor upon seeing the score, and states that points need to be added in areas where DA believes the performance excelled.

g. DA prints out a copy of the comments from the grading rubric to read later. The next morning, DA visits the professor in her office and points out inaccuracies in the grading.

h. DA approaches the professor upon seeing the score, asking for further feedback on the low score. After speaking with the professor, DA heads back to the apartment and vents to his/her roommate about the unfair grade. DA also posts on his/her Instagram story about how the professor "clearly has it out" for DA and is trying to sabotage DA's GPA.

7. KF is rounding as a clinical pharmacist in an interprofessional team with different healthcare providers, eg, physicians, nurses, a social worker, and a physical therapist. The team is discussing discharge planning for a patient who will need to go home on an anticoagulant in a few days. The medical resident would like to discharge the patient on an oral anticoagulant that has convenient dosing and does not require laboratory monitoring. KF is concerned that this particular anticoagulant has not been studied in the disease of the patient. Please rank the following actions in order of effectiveness (most to least): 
e. KF performs a quick literature search and summarizes it for the team. KF works with the team to find another anticoagulant that is suitable for the indication or other solutions that will pose less burden on the patient.

f. KF understands that the resident just wants to make the patient's life easier. It is probably okay to go with what he wanted because medications are prescribed for off-label uses all the time.

g. KF performs a quick literature search and brings it to talk with the attending physician, and asks her to please talk to the resident about the poor choice of anticoagulant.

h. KF leaves a note in the chart to recommend a different agent. $\mathrm{KF}$ is functioning as the drug expert, so no additional information needs to be provided to the team other than the note.

8. JL is a clinical pharmacist working in an inner-city hospital. Those in the pharmacy department have noticed increasing rates of incorrect admission orders because a patient's home medication list was not properly confirmed before writing a medication order. Please rank the following actions in order of effectiveness (most to least):

\section{Place an " $\mathrm{X}$ " in the box regarding your ranking.}

\section{Most \\ Effective}

2

3

e. JL decides to keep a log going forward of all errors and near misses of this kind and encourages her co-workers to do the same. JL will pass the logs on to her pharmacy supervisor so that they will have data to address the issue with appropriate hospital and department authorities.

f. JL is not surprised this is an issue; JL knows from reading literature and the news that almost all hospitals struggle with this and many attempts to address it have failed. $\mathrm{JL}$ is thankful those with more expertise are likely working to address it.

g. JL resolves to call for clarification on all home medication orders that appear to have a discrepancy or involve a highrisk medication, ensuring that JL's patients have the safest care possible.

h. JL encourages everyone in the department to report errors and similar near-miss errors. Over the next month, JL performs a literature search on the topic for evidence-based solutions and analyzes trends in those reported by other pharmacists in the department. Based on these findings, JL recommends changes in the workflow to the appropriate department and hospital authorities to prevent future errors.

9. A month ago, a patient called in asked for a Synthroid refill on a prescription, written so that the generic version is not allowed. The patient just brought the bottle back to ask for another refill, and IG notices that the 2 tablets still left in the container are the generic medication. Clearly no one noticed the error, including the patient, and the patient is not complaining of any ill effects. IG, the current pharmacist on duty, looks in the computer at last months' filling and sees that she was the pharmacist who checked it last month after a new technician filled the prescription. Please rank the following actions in order of effectiveness (most to least):

\section{Place an " $\mathrm{X}$ " in the box regarding your ranking.}

e. IG lets her supervisor and the patient know of the error. She fills the prescription properly this month, making a note in the computer to double-check for the brand name medication on 
future refills. IG educates the new technician on how to properly process such prescriptions.

f. IG notifies the patient of the error, reassuring her that it is not major and should suffer no ill effects if she hasn't already. IG then takes great care to fill the prescription properly this time, performing the entire process herself without technician assistance.

g. IG fills the prescription correctly this time and educates the new technician on how to properly process such prescriptions. IG notifies her supervisor of the error.

h. IG fills the prescription properly this month, making a note in the computer to double-check for the brand name medication on future refills. 